\title{
Suitability of lemon balm (Melissa officinalis L.) extract rich in rosmarinic acid as a potential enhancer of functional properties in cupcakes
}

\author{
Cristina Caleja $^{\mathrm{a}, \mathrm{b}}$, Lillian Barros ${ }^{\mathrm{a}}$, João C.M. Barreira ${ }^{\mathrm{a}}$, Ana Ciric ${ }^{\mathrm{c}}$, Marina Sokovic ${ }^{\mathrm{c}}$, \\ Ricardo C. Calhelha $^{\mathrm{a}}$, M. Beatriz ${ }^{\mathrm{b}}$, P.P. Oliveira ${ }^{\mathrm{b}}$, Isabel C.F.R. Ferreira ${ }^{\mathrm{a}, *}$ \\ a Centro de Investigação de Montanha (CIMO), Instituto Politécnico de Bragança, Campus de Santa Apolónia, 5300-253 Bragança, Portugal \\ ${ }^{\mathrm{b}}$ REQUIMTE/LAQV, Faculty of Pharmacy, University of Porto, Rua Jorge Viterbo Ferreira, No. 228, 4050-313 Porto, Portugal \\ ' Universityof Belgrade, Department of Plant Physiology, Institute for Biological Research "Siniša Stanković", Bulevar Despota Stefana 142, 11000 Belgrade, Serbia
}

\section{A R T I C L E I N F O}

\section{Keywords:}

Cupcake

Bioactivity

Lemon balm

Potassium sorbate (E202)

Proximate composition

Colour parameters

Fatty acids

\begin{abstract}
A B S T R A C T
Melissa officinalis (lemon balm) and its extracts have been frequently reported as possessing bioactive properties, offering the potential for use in development/enrichment of food products with additional functional capabilities, providing health benefits to consumers. The antioxidant, antibacterial and antifungal activity of lemon balm extract, as well as its potential hepatotoxicity were thoroughly evaluated. The extracts were then incorporated into cupcakes and their preserving effect, chemical composition, colour parameters and antioxidant activity were compared with those provided by potassium sorbate. In general, the variables with the largest differences among different storage times were energy level, sucrose, glucose, palmitic acid (C6:0) and oleic acid (C18:1n9). On the other hand, $L^{*}$ (top), $a^{*}$ (top), $b^{*}$ (top), $\mathrm{pH}$, capric acid (C10:0) and lauric acid (C12:0) showed the greatest variation according to cupcake formulation. The results observed indicate that the lemon balm extract rich in rosmarinic acid can provide advantageous functional properties to bakery products.
\end{abstract}

\section{Introduction}

Cakes, biscuits and cookies are bakery products appreciated worldwide and consumed by individuals from different age groups and social ranks. Some of the reasons underlying this success include their affordable cost, great availability of flavours and textures and average shelf-life (Caleja, Barros, Antonio, Oliveira, \& Ferreira, 2017; Gandhi et al., 2001; Jeddou et al., 2017). Owing to the generally high fat content of pastry products, these are particularly prone to oxidative deterioration, demanding the employment of effective antioxidants to maintain their integral quality (Bera, Lahiri, \& Nag, 2006). However, the commonly used artificial antioxidants, especially if consumed excessively, were associated with several adverse effects on consumers' health (Lennerz et al., 2015). This scenario boosts the search for antioxidants obtained from natural species, which often present high levels of polyphenolic compounds, tocopherols, ascorbic acid or carotenoids, all representing good alternatives to artificial antioxidants, such as BHA or BHT (Maqsood, Benjakul, \& Shahidi, 2013), which is also in line with the current consumers' demand for healthier, safer and more convenient food (Shim et al., 2011).

Furthermore, in addition to the preserving ability of different natural extracts, they contain compounds with excellent bioactivity, which might represent a way to improve the overall effect of pastry products consumption. In fact, several studies have proven the excellent preservative capacity of different plant extracts in different food matrices. Foeniculum vulgare Mill. And Matricaria recutita L., for instance, are two examples of medicinal plants with various beneficial physiological properties, namely in the prevention and treatment of several diseases (Roby, Sarhan, Selim, \& Khalel, 2013). Furthermore, extracts from both plants, most likely due to their antioxidant and antimicrobial properties, showed to be highly effective in preserving different food products, such as cottage cheese (Caleja, Barros, Antonio, Ciric, Soković et al., 2015; Caleja, Barros, Antonio, Ciric, Barreira et al., 2015), yoghurts (Caleja et al., 2016) and biscuits (Caleja et al., 2017). Obviously, in addition to the achieved preservative effect, plant extracts can improve the bioactivity levels in the functionalized food products, without changing their appearance or nutritional value. This double preservingfunctionalizing effect was also observed in a "Serra da Estrela" cheese (a Portuguese specialty cheese), when incorporated with aqueous extracts Castanea sativa Mill. and Ocimum basilicum L. (Carocho, Barreira et al., 2016; Carocho, Barros et al., 2016).

The purpose of the present study was to obtain lemon balm extracts rich in rosmarinic acid (ERA), and to validate their antioxidant and antimicrobial properties and verify their lack of toxicity. Further

\footnotetext{
* Corresponding author.

E-mail address: iferreira@ipb.pt (I.C.F.R. Ferreira).
} 
incorporation of these extracts into cupcakes was used to verify their suitability as an alternative to the commonly used artificial additive (potassium sorbate).

\section{Materials and methods}

\subsection{Standards and reagents}

Fatty acids methyl ester (FAME) reference standard mixture 37 (standard 47885-U) was purchased from Sigma-Aldrich (St. Louis, Missouri, USA), as also sugar standards (L-rhamnose, L- $(+)$-arabinose, D-(-)-fructose, D-(+)-glucose, D-(+)-sucrose, D-(-)-mannitol, D$(+)$-trehalose, $\mathrm{D}-(+)$-maltose, $\mathrm{D}-(+)$-raffinose and $\mathrm{D}-(+)$-melezitose) and Trolox (6-hydroxy-2,5,7,8-tetramethylchroman-2-carboxylic acid). Acetonitrile (HPLC grade) was purchased from Fisher Scientific (Lisbon, Portugal). 2,2-Diphenyl-1-picrylhydrazyl (DPPH) was obtained from Alfa Aesar (Ward Hill, Massachusetts, USA). The standard, rosmarinic acid was from Extrasynthese, Genay Cedex, France. All other solvents and reagents were obtained from common sources and water was treated in Milli-Q water purification system (Millipore Corporation, Billerica, Massachusetts, USA).

\subsection{Natural ingredients}

\subsubsection{Preparation of lemon balm extract rich in rosmarinic acid}

Commercial samples of Melissa officinalis L. (lemon balm) were provided by Pragmático Aroma Lda. ("Mais Ervas") based in Trás-osMontes, Portugal (three bags containing $\sim 300 \mathrm{~g}$ each). The lemon balm extract rich in rosmarinic acid (ERA) were obtained using an ultrasonic device (QSonica sonicators, model CL-334, Newtown, CT, USA) comprising an ultrasound power in the range between 100 and $500 \mathrm{~W}$ at a frequency of $20 \mathrm{kHz}$, equipped with a digital timer. The dried powdered leaf samples $(1.5 \mathrm{~g})$ were extracted with $50 \mathrm{ml}$ of a mixture of ethanol:water (30:70), for $33 \mathrm{~min}$ using $371 \mathrm{~W}$ ultrasound power, the temperature was monitored in order to be below $30-35^{\circ} \mathrm{C}$ (Caleja et al., 2017). After evaporating the ethanol, the samples were lyophilized and stored in a desiccator at room temperature (average $25^{\circ} \mathrm{C}$ ), protected from light, until further analysis.

Potassium sorbate 99\% (E202) was used as an artificial additive (Acros Organics, Geel, Belgium).

\subsubsection{Chemical characterization}

The lyophilized extract obtained from lemon balm was re-dissolved in the extraction solvent (mixture of ethanol:water (30:70), filtered through a $0.22 \mu \mathrm{m}$ nylon filter and submitted to LC-DAD-ESI/MSn analysis. The chromatographic data were acquired from Dionex Ultimate 3000 UPLC (Thermo Scientific, San Jose, CA, USA), as previously described by Bessada, Barreira, Barros, Ferreira, and Oliveira (2016). Chromatographic separation was achieved with a Waters Spherisorb S3 ODS-2 C18 $(3 \mu \mathrm{m}, 4.6 \times 150 \mathrm{~mm}$, Waters, Milford, MA, USA) column thermostatted at $35^{\circ} \mathrm{C}$. The solvents used were: (A) $0.1 \%$ formic acid in water, (B) acetonitrile. The elution gradient established was isocratic $15 \%$ B ( $5 \mathrm{~min}$ ), $15-20 \%$ B ( $5 \mathrm{~min}$ ), $20-25 \%$ B (10 min), $25-35 \%$ B (10 $\mathrm{min}), 35-50 \% \mathrm{~B}(10 \mathrm{~min})$, and re-equilibration of the column, using a flow rate of $0.5 \mathrm{ml} / \mathrm{min}$ and an injection volume of $10 \mu \mathrm{l}$. Double online detection was carried out in the DAD using 280 and $370 \mathrm{~nm}$ as preferred wavelengths and in a mass spectrometer (MS) connected to HPLC system via the DAD cell outlet.

MS detection was performed in negative mode, using a Linear Ion Trap LTQ XL mass spectrometer (ThermoFinnigan, San Jose, CA, USA) equipped with an ESI source. Nitrogen served as the sheath gas (50 psi); the system was operated with a spray voltage of $5 \mathrm{kV}$, a source temperature of $325^{\circ} \mathrm{C}$, a capillary voltage of $-20 \mathrm{~V}$. The tube lens offset was kept at a voltage of $-66 \mathrm{~V}$. The full scan covered the mass range from $m / z 100$ to 1500 . The collision energy used was 35 (arbitrary units). Data acquisition was carried out with Xcalibur $^{\circledast}$ data system
(ThermoFinnigan, San Jose, CA, USA).

Rosmarinic acid was identified by comparing its retention times, UV-vis and mass spectra with the standard compound. For quantitative analysis, a calibration curve of rosmarinic acid was constructed based on the UV signal ( $\mathrm{y}=191291 \mathrm{x}-652903, R^{2}=0.999$ ). The results were expressed as $\mathrm{mg} / \mathrm{g}$ of extract.

\subsubsection{Evaluation of antioxidant properties}

The lyophilized samples were re-dissolved in ethanol $(5 \mathrm{mg} / \mathrm{ml})$ and successively diluted to allow determining the corresponding $\mathrm{EC}_{50}$ values (sample concentration providing $50 \%$ of antioxidant activity or 0.5 of absorbance in the reducing power assay).

Following the previously described protocols (Barros et al., 2013), DPPH radical-scavenging activity and reducing power were evaluated using ELX800 microplate reader (Bio-Tek Instruments, Inc., Winooski, VT, USA) at 515 and $690 \mathrm{~nm}$, respectively. Additionally, $\beta$-carotene bleaching inhibition and lipid peroxidation inhibition, were respectively evaluated by measuring the colour decay of a $\beta$-carotene solution as induced by a linoleate solution (at $470 \mathrm{~nm}$ ) and by using the thiobarbituric acid reactive substances (TBARS) assay (at $532 \mathrm{~nm}$ ). Trolox was used as positive control in all assays.

\subsubsection{Evaluation of toxicity}

The hepatotoxicity was evaluated following a cell line obtained from porcine liver acquired from certified abattoirs (Guimarães et al., 2013). A phase-contrast microscope was used to monitor the growth of the cell cultures, which were sub-cultured and plated in 96 well plates (density of $1.0 \times 10^{4}$ cells/well). Dulbecco's modified Eagle's medium (DMEM) was used, supplemented with FBS (10\%), penicillin (100 U/ $\mathrm{ml})$ and streptomycin $(100 \mu \mathrm{g} / \mathrm{ml})$. Ellipticine was used as a positive control. The results were expressed as $\mathrm{GI}_{50}$ values in $\mu \mathrm{g} / \mathrm{ml}$ (sample concentration that inhibited $50 \%$ of the net cell growth).

\subsubsection{Evaluation of antimicrobial properties}

Antibacterial activity was evaluated according to a previously described methodology (Soković, Glamoćlija, Marin, Brkić, \& van Griensven, 2010) using four Gram-negative bacteria: Escherichia coli (ATCC 35210), Pseudomonas aeruginosa (ATCC 27853), Salmonella typhimurium (ATCC 13311), Enterobacter cloacae (ATCC 35030), and four Gram-positive bacteria: Staphylococcus aureus (ATCC 6538), Bacillus cereus (clinical isolate), Micrococcus flavus (ATCC 10240), and Listeria monocytogenes (NCTC 7973). The minimum inhibitory (MIC) and minimum bactericidal (MBC) concentrations were determined and streptomycin and ampicillin were used as positive controls.

Furthermore, the antifungal activity was evaluated using eight reference species: Aspergillus fumigatus (ATCC 1022), Aspergillus ochraceus (ATCC 12066), Aspergillus versicolor (ATCC 11730), Aspergillus niger (ATCC 6275), Penicillium funiculosum (ATCC 36839), Penicillium ochrochloron (ATCC 9112), Trichoderma viride (IAM 5061) and Penicillium verrucosum var. cyclopium (food isolate) (Soković \& van Griensven, 2006). The MIC and minimum fungicidal concentration (MFC) were determined. Bifonazole and ketoconazole were used as positive controls.

\subsection{Preparation of cupcakes}

To prepare the cupcakes, a traditional base recipe was followed: four eggs were thoroughly mixed with $100 \mathrm{~g}$ of sugar and lemon zest. Then, $100 \mathrm{~g}$ of melted butter were added, combined with $125 \mathrm{~g}$ of flour and $2 \mathrm{~g}$ of yeast powder, and further mixed with a hand mixer at $450 \mathrm{~W}$ (MFQ 3540, Bosch, Munich, Germany). The ERA (lyophilized) or the potassium sorbate powder were mixed with the dry ingredients. The dough was distributed in silicone baking cups and placed in the oven (HE-635, Teka, Haiger, Germany) for $15 \mathrm{~min}$ at $180^{\circ} \mathrm{C}$. Three different lots (12 per lot, further divided in 3 groups of 4 cupcakes for each storage time) of cupcakes were prepared: i) control cupcakes without 
any additives; ii) cupcakes with $1.1 \mathrm{~g}$ of ERA; iii) cupcakes with $1.1 \mathrm{~g}$ of potassium sorbate (E202). All samples were lyophilized, finely crushed and analysed (in triplicate), immediately after preparation, after three days of storage or after five days of storage (cupcakes were stored at room temperature and packed in a sealed plastic bag covered with aluminium paper).

\subsection{Evaluation of the colour parameters and $\mathrm{pH}$ of cupcakes}

Colour was measured on the top and on the bottom (in three different points in each case) of all cupcakes using a colorimeter (model CR-400, Konica Minolta Sensing Inc., Tokyo, Japan). The illuminate C was used, with a diaphragm aperture of $8 \mathrm{~mm}$, after being calibrated against a standard white tile. The CIE $L^{*}$ (lightness), $a^{*}$ (greenness/ redness), $b^{*}$ (blueness/yellowness) colour space values were registered using "Spectra Magic Nx" (version CM-S100W 2.03.0006) (Fernandes et al., 2012).

The $\mathrm{pH}$ of the samples was measured in three different points directly in the samples with a $\mathrm{HI} 99,161 \mathrm{pH}-m e t e r$ (Hanna Instruments, Woonsocket, Rhode Island, USA).

\subsection{Evaluation of the nutritional properties}

Following the AOAC methods (AOAC, 2016), the contents of protein, fat and ash, was determined. Total energy was calculated following the equation:

Energy $(\mathrm{kcal})=4 \times(\mathrm{g}$ proteins $+\mathrm{g}$ carbohydrates $)+9 \times(\mathrm{g}$ lipids $)$

In addition, fatty acids and free sugars were also determined. Fatty acids were analysed in hexane extracts (obtained in a Soxhlet apparatus) by gas-chromatography coupled to a flame ionization detector (GC-FID). Fatty acids were identified by comparison with standards (standard 47885, Sigma-Aldrich, St. Louis, Missouri, USA) and expressed as relative percentages of each fatty acid (Barros et al., 2013). Free sugars were determined in hydro-ethanolic extracts obtained from defatted samples by HPLC coupled to a refraction index (RI) detector (Barros et al., 2013), identified by comparison with standards, and further quantified $(\mathrm{g} / 100 \mathrm{~g}$ of cupcake) based on the internal standard (melezitose).

\subsection{Antioxidant activity}

Three independent samples $(\approx 3 \mathrm{~g}$ ) of each cupcake formulation and storage time were added to a mixture of ethanol:water (30:70) for $1 \mathrm{~h}$, using a procedure previously described by Caleja et al. (2016). After removing the solvent, the extracts were dissolved to a final concentration of $200 \mathrm{mg} / \mathrm{ml}$. The antioxidant activity evaluation was performed using two in vitro assays: 2,2-diphenyl-1-picrylhydrazyl (DPPH) radical-scavenging activity and reducing power (RP), following the experimental methodologies adopted by the authors (Caleja et al., 2016).

\subsection{Statistical analysis}

The statistical tests were performed with a $5 \%$ significance level using IBM SPSS Statistics for Windows, version 22.0. (IBM Corp., Armonk, NY, USA). Except for antimicrobial assays results, data were expressed as mean \pm standard deviation; differences in the number of decimal places are justified by the magnitude of standard deviations.

An analysis of variance (ANOVA) with type III sums of squares was performed using the general linear model (GLM) procedure, to compare the prepared cupcakes. The dependent variables were analysed using 2way ANOVA with the factors "cupcake formulation" (CF) and "storage time" (ST). In parameters showing results with a statistically significant interaction among factors, those were evaluated simultaneously by the estimated marginal means plots for all levels of each factor. In cases with no statistical significant interaction, means were compared using Tukey's multiple comparison test, after checking the equality of variances through a Levene's test.

In addition, a linear discriminant analysis (LDA) was used to compare the effects of CF and ST on the differences observed in the evaluated parameters. A stepwise technique was applied, considering the Wilks' $\lambda$ test with the usual probabilities of $F$ (3.84 to enter and 2.71 to be removed) for variable selection. The main purpose was estimating the relationship between single categorical dependent variables (cupcake formulations or storage times) and the quantitative independent variables (evaluated parameters), thereby determining which independent variables contributed more to the differences in the average score profiles of both factors. To verify the significance of the canonical discriminating functions, Wilk's $\lambda$ test was used. A leaving-one-out cross validation procedure was carried out to assess the model performance.

\section{Results and discussion}

One of the top advantages associated with the replacement of synthetic additives by natural ones derives from the high bioactivity of the latter, allowing to simultaneously preserve and functionalize a determined food product. In fact, this binary effect of natural compounds, or their corresponding enriched extracts, was previously assayed in different products such as yogurts (Caleja et al., 2016), cottage cheese (Caleja, Barros, Antonio, Ciric, Soković et al., 2015; Caleja, Barros, Antonio, Ciric, Barreira et al., 2015), cheese (Carocho, Barreira et al., 2016; Carocho, Barros et al., 2016), biscuits (Caleja et al., 2017; Carocho, Barreira, Bento, Morales, \& Ferreira, 2014; Carocho, Barreira, et al., 2015), or bread (Sciarini, Ribotta, León, \& Pérez, 2012; Singh, Jha, Chaudhary, \& Upadhyay, 2012), just to cite a few.

Rosemary Extract (E392) is the only allowed food preservative extract within the European Union (Carocho, Morales, \& Ferreira, 2015). This additive is extracted from rosemary (Rosmarinus officinalis L.) leaves and stems, and rosmarinic acid is one of the main constituents. Nowadays, in the food industry thousands of plants have been screened for suitability to be used as preservatives. In the present work, the aqueous extract of $M$. officinalis (lemon balm), previously reported as containing high levels of rosmarinic acid (Barros et al., 2013; Caleja et al., 2017; Döring et al., 2014), was used as a natural preserver/ functionalizing agent in cupcake formulations. Before the extracts incorporation, their bioactivity was characterized, specifically by evaluated antioxidant activity, antibacterial activity, antifungal activity and potential hepatotoxicity, which are among the acknowledged effects of M. officinalis (Shakeri, Sahebkar, \& Javadid, 2016).

Considering the results obtained in four distinct assays (Table 1), the strong antioxidant activity of ERA is obvious, especially concerning TBARS formation inhibition $\left(\mathrm{EC}_{50}=25 \pm 2 \mu \mathrm{g} / \mathrm{ml}\right.$ extract), reducing power $\left(\mathrm{EC}_{50}=49 \pm 1 \mu \mathrm{g} / \mathrm{ml}\right.$ extract) and DPPH scavenging activity $\left(\mathrm{EC}_{50}=79 \pm 2 \mu \mathrm{g} / \mathrm{ml}\right.$ extract$)$, which is in line with previously obtained results (Barros et al., 2013; Dias, Barros, Sousa, \& Ferreira, 2012; Kamdem et al., 2013; Pereira et al., 2015; Pereira et al., 2017).

The antibacterial (Table 1) is noteworthy since the ERA gave lower MIC and MBC than streptomycin and ampicillin for all bacterial species, Gram positive or Gram negative, except for Staphylococcus aureus. Among Gram positive bacteria, the most sensitive were Enterobacter cloacae (MIC $=0.075 \mathrm{mg} / \mathrm{ml}$ extract; $\mathrm{MFC}=0.15 \mathrm{mg} / \mathrm{ml}$ extract). The MIC and MBC values are slightly better, despite comparable, to those obtained with the decoctions of the same species (Carocho, Barros, et al., 2015; Shakeri et al., 2016). Nevertheless, the antifungal activity was even stronger, especially in comparison to ketoconazole, as it might be confirmed by the tenfold differences in MIC among some fungal species such as Aspergillus ochraceus. Actually, and except for the MFC values measured in Aspergillus fumigatus, Penicillium funiculosum and Penicillium ochrochloron, the $M$. officinalis extract showed higher activity 


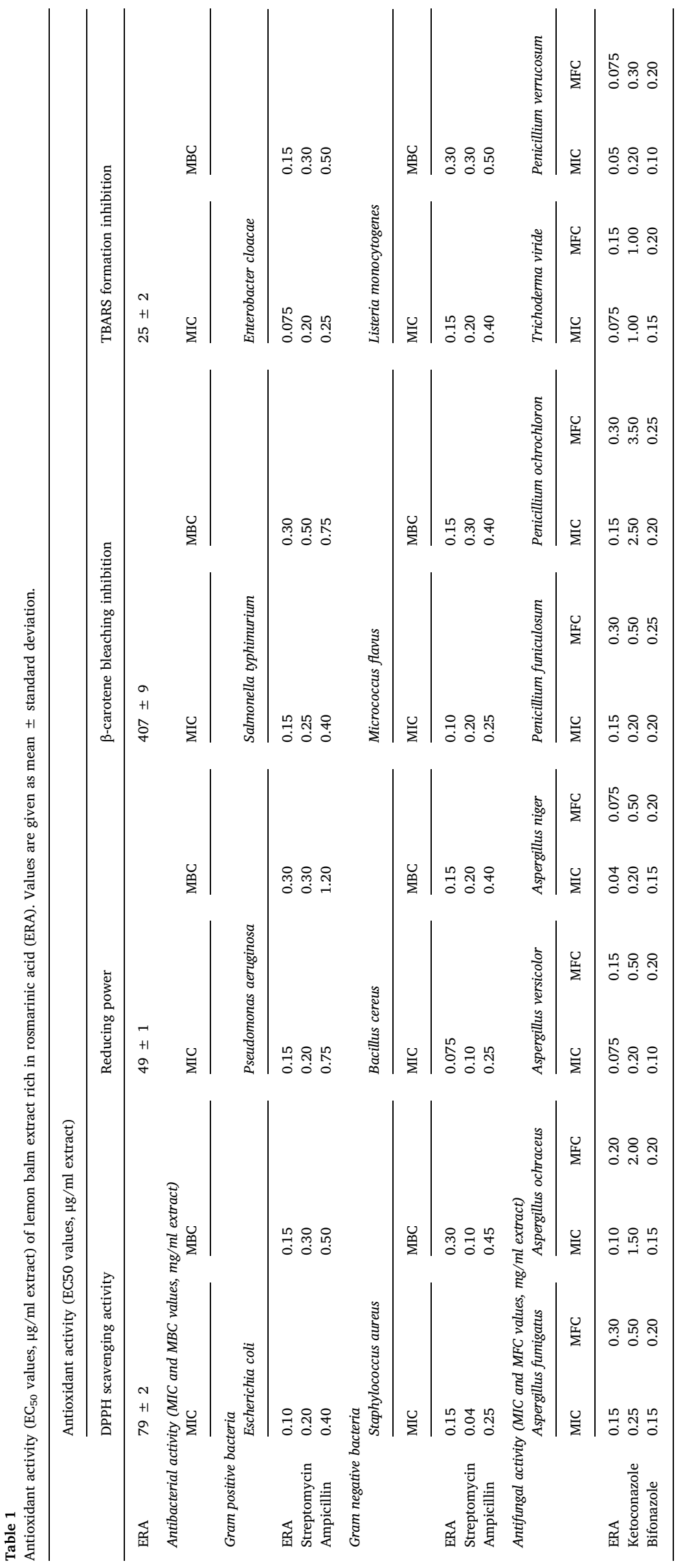


than ketoconazole and bifonazole against all fungal species, either considering MIC or MFC results. A good level of antifungal activity was also observed when evaluating $M$. officinalis activity against related fungal species (Shakeri et al., 2016) as well as against phytopathogenic fungi (El Ouadi et al., 2017).

Interestingly, the ERA did not show acute cytotoxicity, as revealed by maintenance of the PLP cell culture (the $\mathrm{GI}_{50}$ value could not be determined, since cells maintain their growth when exposed to the maximum tested extract concentration: $400 \mu \mathrm{g} / \mathrm{ml}$ ).

Furthermore, the quantification of rosmarinic acid $(181 \pm 3 \mathrm{mg}$ of rosmarinic acid/g of extract) in the optimized extract obtained from lemon balm was also determined.

According to the former advantageous properties, the ERA were incorporated into cupcakes (standard formulation) aiming to add some beneficial effects to their consumption. Besides comparing the newly formulated cupcakes with the traditional recipe (no additives included), a set of cupcakes containing the commonly used preservative, potassium sorbate (E202), was also prepared and evaluated. Furthermore, all performed assays were done at three different periods (baking day, after 3 days of storage and after 5 days of storage).

\subsection{Characterization of different cupcake formulations}

Owing to their high consumption level, cupcakes might be considered as a suitable product to test different functionalization approaches. In fact, this particular food product was previously functionalized with xanthophylls (Xavier, Carvajal-Lérida, Garrido-Fernández, \& Pérez-Gálvez, 2017) or anthocyanin-enriched extracts (AbdelMoemin, 2016), besides being formulated with different flours (Kim \& Shin, 2014), trying to fulfil the current consumer preference towards food products containing natural additives instead of synthetic compounds.

In the present work, three different cupcake formulations were prepared: i) control (cupcakes without any incorporated extract); ii) cupcakes with ERA; iii) cupcakes with added potassium sorbate. Furthermore, the potential differences among formulations were also evaluated throughout time, by analysing samples from cupcakes submitted to different storage times: preparation day, 3 days after preparation and 5 days after preparation. In this sense, two different factors (CF and ST) might contribute to the variability among different analysed parameters. Therefore, it was also mandatory to verify their interaction $(\mathrm{CF} \times \mathrm{ST})$, in order to check if the effect of one factor depended on the variation of the other. Concerning the parameters where a significant interaction was found $(p<.050)$, the statistical classification was not possible, and the results were discussed based on the estimated marginal means (EMM) plots (data might be provided upon request).

The proximate analysis results (Table 2) showed significant differences, either among different formulations, as well as in result of ST, for almost all parameters, except glucose $(p=.533)$ and sucrose $(p=.962)$ regarding $\mathrm{CF}$, thereby indicating a generally more significant effect of ST in comparison to CF. However, the interaction was also significant in all cases, except protein content $(p=.352)$, allowing classification of the results only in this case. As indicated, protein content was statistically higher in control samples $(7.3 \pm 0.5 \mathrm{~g} / 100 \mathrm{~g})$, among different $\mathrm{CF}$, and in samples stored during 3 days $(7.3 \pm 0.4 \mathrm{~g}$ / $100 \mathrm{~g}$ ), in what concerns ST. Considering the EMM plots, additional overall conclusions could also be obtained for the remaining parameters: moisture (as expected) tended to decrease with time ( $36 \pm 3 \mathrm{~g} / 100 \mathrm{~g}$ at preparation day, $30 \pm 4 \mathrm{~g} / 100 \mathrm{~g}$ after 5 days of storage), showing also lower values ( $30 \pm 4 \mathrm{~g} / 100 \mathrm{~g})$ in control samples. These differences are linked to the variation in carbohydrates (since these are calculated by difference), which increased with time (38 $\pm 1 \mathrm{~g} / 100 \mathrm{~g}$ at preparation day to $43 \pm 2 \mathrm{~g} / 100 \mathrm{~g}$ after 5 days of storage), and registered maximum values in control samples. The most noticeable difference regarding fat content resulted from ST, as indicated by the higher contents $(20 \pm 1 \mathrm{~g} / 100 \mathrm{~g})$ quantified in samples stored for 5 days. Energy values increased along ST (345 $\pm 12 \mathrm{kcal}$ to $378 \pm 21 \mathrm{kcal}$ ) and showed the highest values in control samples, most likely due to carbohydrate content.

Despite the relevance of nutritional parameters, the visual appearance is also highly important, as it represents the primary consumers' acceptability criterion. In Fig. 1, the photographs of each of the cupcakes samples are shown where visually the results described can be verified and the similarities between the control cupcake (Fig. 1A) and cupcake with potassium sorbate (Fig. 1C) distinguished from cupcake with lemon balm extract (Fig. 1B) which presents a more "integral aspect". Accordingly, the colour parameters ( $L^{*}:$ lightness, $a^{*}$ : redness and $b^{*}$ : yellowness) were evaluated in the top and bottom crusts of the prepared cupcakes (Table 3). All measured parameters showed significant differences among different $\mathrm{CF}$, while no statistical differences at all were detected for cupcake samples stored during different periods. The interaction among factors was again significant in most cases, with $b^{*}$ (top) as the only parameter that was not affected cooperatively by both factors $(p=.809)$. This parameter showed statistically higher values $(50 \pm 5)$ in cupcakes with added potassium sorbate. According to the EMM plots, it was possible to conclude that cupcakes incorporating ERA presented lower $L^{*}$ (top: $56 \pm 3$ ), $a^{*}$ (top: $6 \pm 2$ and bottom: $11 \pm 4$ ) and $b^{*}$ (top: $33 \pm 2$ and bottom: $34 \pm 2$ ) than the remaining formulations, thereby indicating that this particular type of cupcake might be less visually attractive (especially for younger consumers).

Despite a certain tendency for higher values in cupcakes with added potassium sorbate and lower values in control cupcakes, differences in $\mathrm{pH}$ values were barely noticeable.

Concerning fatty acid profile, the main molecules (Table 4) were

Table 2

Nutritional composition ( $\mathrm{g} / 100 \mathrm{~g}$ ) and energy (kcal) values for different cupcake formulations (CF) and storage times (ST). Results are presented as mean \pm standard deviation. ${ }^{1}$

\begin{tabular}{|c|c|c|c|c|c|c|c|c|c|}
\hline & & Moisture & Fat & Protein & Ash & Carbohydrates & Glucose & Sucrose & Energy \\
\hline \multirow[t]{4}{*}{$\mathrm{CF}$} & Control & $30 \pm 4$ & $20 \pm 1$ & $7.3 \pm 0.5 \mathrm{a}$ & $0.70 \pm 0.04$ & $42 \pm 3$ & $0.17 \pm 0.02$ & $37 \pm 4$ & $375 \pm 23$ \\
\hline & Lemon balm extract rich in rosmarinic acid (ERA) & $35 \pm 2$ & $19 \pm 1$ & $6.8 \pm 0.4 b$ & $0.67 \pm 0.05$ & $39 \pm 1$ & $0.19 \pm 0.05$ & $37 \pm 4$ & $350 \pm 11$ \\
\hline & Potassium sorbate (E202) & $33 \pm 4$ & $19 \pm 1$ & $6.9 \pm 0.4 b$ & $0.75 \pm 0.05$ & $40 \pm 3$ & $0.18 \pm 0.05$ & $37 \pm 4$ & $356 \pm 15$ \\
\hline & ANOVA $p$-value $(\mathrm{n}=27)^{2}$ & $<.001$ & .002 & $<.001$ & $<.001$ & $<.001$ & .533 & .962 & $<.001$ \\
\hline \multirow[t]{4}{*}{ ST } & 0 days & $36 \pm 3$ & $18 \pm 1$ & $6.8 \pm 0.4 b$ & $0.74 \pm 0.05$ & $38 \pm 1$ & $0.20 \pm 0.05$ & $34 \pm 2$ & $345 \pm 12$ \\
\hline & 3 days & $32 \pm 2$ & $19 \pm 1$ & $7.3 \pm 0.4 \mathrm{a}$ & $0.70 \pm 0.05$ & $40 \pm 2$ & $0.21 \pm 0.04$ & $39 \pm 3$ & $358 \pm 8$ \\
\hline & 5 days & $30 \pm 4$ & $20 \pm 1$ & $6.9 \pm 0.5 b$ & $0.69 \pm 0.05$ & $43 \pm 2$ & $0.13 \pm 0.04$ & $39 \pm 4$ & $378 \pm 21$ \\
\hline & ANOVA $p$-value $(\mathrm{n}=27)^{3}$ & $<.001$ & $<.001$ & $<.001$ & .004 & $<.001$ & $<.001$ & $<.001$ & $<.001$ \\
\hline $\mathrm{CF} \times \mathrm{ST}$ & $p$-value $(\mathrm{n}=81)^{4}$ & $<.001$ & $<.001$ & .358 & $<.001$ & $<.001$ & $<.001$ & $<.001$ & $<.001$ \\
\hline
\end{tabular}

${ }^{1}$ The results presented for each CF included the contribution of values measured in all ST; likewise, results for each ST were obtained considering the values measured for all CF.

${ }^{2}$ If $p<.050$, the corresponding parameter presented a significantly different value for at least one CF.

${ }^{3}$ If $p<.050$, the corresponding parameter presented a significantly different value for at least one ST.

${ }^{4} p<.050$ indicates a significant interaction among factors, thereby precluding performing multiple comparison tests. 

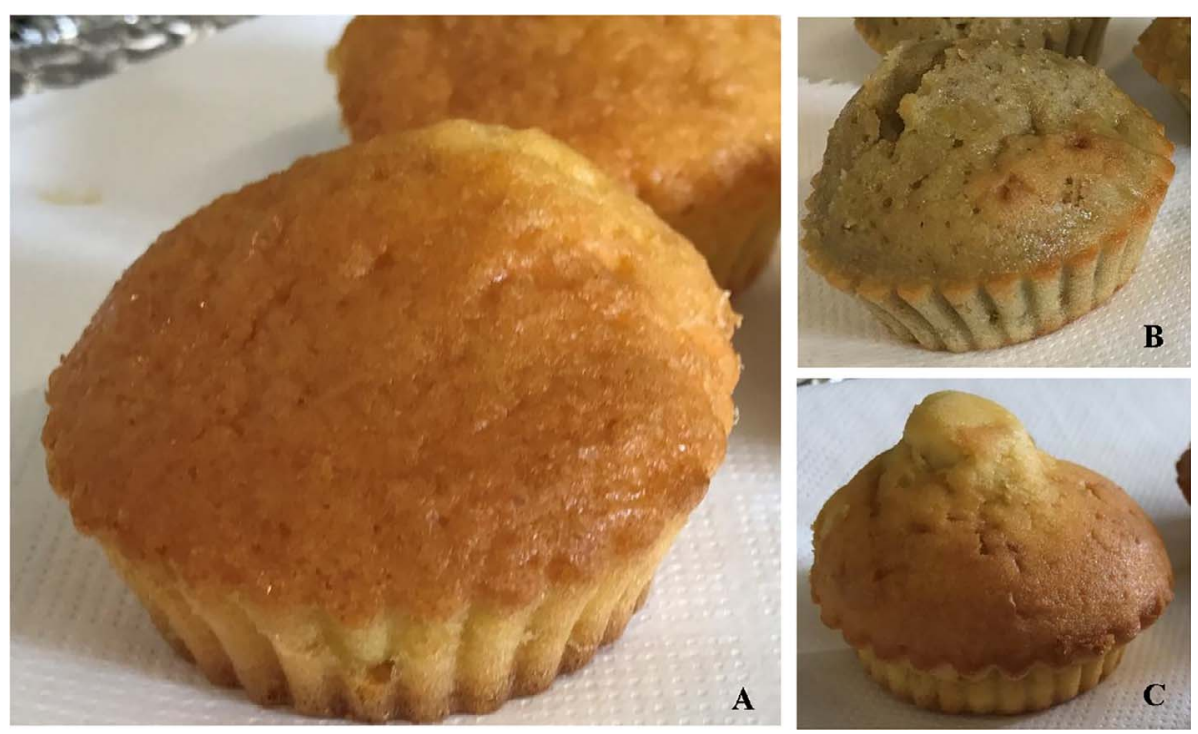

Fig. 1. Appearance of cupcakes samples along shelf life (A) cupcake control, (B) cupcake with lemon balm extract rich in rosmarinic acid and (C) cupcake with potassium sorbate.

also affected cooperatively by CF and ST, except in the case of myristic acid (C14:0) and palmitic acid (C16:0). Regarding the individual effect of each factor, caproic acid (C6:0), C14:0 and stearic acid (C18:0) did not show significant variation among different $\mathrm{CF}$, in line with that verified for lauric acid (C12:0) and C14:0 concerning the ST effect. Accordingly, it was only possible to present the statistical classification in the case of C16:0, which showed the highest values in cupcakes functionalized with ERA and in non-stored cupcakes, for each respective factor. In the remaining cases, it was possible to conclude that butyric acid (C4:0) presented lower values $(4 \pm 1 \%)$ in cupcakes with ERA and in control cupcakes $(4 \pm 1 \%)$, C6:0 $(2.3 \pm 0.4 \%)$ and capric acid (C10:0) $(3.2 \pm 0.5 \%)$ presented lower percentages at the preparation day, C10:0 $(4.3 \pm 0.5 \%)$ and $\mathrm{C} 12: 0(4.5 \pm 0.4 \%)$ showed higher levels in cupcakes without additives (control), C18:0 tended to lower values $(9.5 \pm 0.4 \%)$ after 5 days of storage and oleic acid (C18:1n9) presented lower percentages in control $(23 \pm 1 \%)$ samples and in non-stored $(28 \pm 1 \%)$ samples. The same tendencies were reflected in grouped fatty acids (SFA, MUFA and PUFA), mostly showing a higher tendency towards saturated fatty acids with storage, when compared to the more sensitive unsaturated forms.

Considering the purpose of providing a new food product with specific bioactivity, the improvement in the antioxidant activity achieved in cupcakes incorporated with ERA was evident. The average $\mathrm{EC}_{50}$ values for $\mathrm{DPPH}$ scavenging activity (obtained for all storage times) were $68 \pm 12 \mathrm{mg} / \mathrm{ml}$ extract for control cupcakes, $41 \pm 12 \mathrm{mg} / \mathrm{ml}$ extract for cupcakes incorporated with ERA and
$44 \pm 18 \mathrm{mg} / \mathrm{ml}$ extract for cupcakes with added potassium sorbate. However, the antioxidant activity increase was more noticeable in the reducing power assay: $\mathrm{EC}_{50}$ values $=70 \pm 12 \mathrm{mg} / \mathrm{ml}$ extract for control cupcakes, $9 \pm 1 \mathrm{mg} / \mathrm{ml}$ extract for cupcakes incorporated with ERA and $37 \pm 13 \mathrm{mg} / \mathrm{ml}$ extract for cupcakes with added potassium sorbate, clearly highlighting cupcakes incorporated with ERA as the ones having highest bioactive potential.

In either case, a significant percentage of the detected antioxidant activity was lost throughout storage, as indicated by the $\mathrm{EC}_{50}$ values for DPPH scavenging activity (0 days: $44 \pm 18 \mathrm{mg} / \mathrm{ml}$ extract; 3 days: $54 \pm 7 \mathrm{mg} / \mathrm{ml}$ extract; 5 days: $65 \pm 14 \mathrm{mg} / \mathrm{ml}$ extract) and reducing power ( 0 days: $29 \pm 15 \mathrm{mg} / \mathrm{ml}$ extract; 3 days: $39 \pm 19 \mathrm{mg} / \mathrm{ml}$ extract; 5 days: $48 \pm 21 \mathrm{mg} / \mathrm{ml}$ extract).

\subsection{Linear discriminant analysis}

After evaluating several individual changes among the studied parameters, either due to CF or ST effects, the next step was identifying the parameters with the most significant changes for each factor, as well as the ones more highly correlated to each factor level $(0,3$ or 5 days in one case and control, cupcakes functionalized with lemon balm extract or with added potassium sorbate in the other). With that purpose in mind, two linear discriminant analysis (LDA) were performed, intended to respectively evaluate the association between CF or ST (categorical dependent variables) and the matrix of obtained results (quantitative independent variables). The significant independent variables were

Table 3

Colour parameters evaluated in cupcake formulations (CF) and storage time (ST). Results are presented as mean \pm standard deviation ${ }^{1}$.

\begin{tabular}{|c|c|c|c|c|c|c|c|c|}
\hline & & $L^{*}$ (top) & $a^{*}$ (top) & $b^{*}$ (top) & $L^{*}$ (bottom) & $a^{*}$ (bottom) & $b^{*}$ (bottom) & $\mathrm{pH}$ \\
\hline \multirow[t]{4}{*}{$\mathrm{CF}$} & Control & $64 \pm 5$ & $12 \pm 4$ & $46 \pm 2 b$ & $56 \pm 3$ & $15 \pm 2$ & $37 \pm 3$ & $7.1 \pm 0.2$ \\
\hline & Lemon balm extract rich in rosmarinic acid (ERA) & $56 \pm 3$ & $6 \pm 2$ & $33 \pm 2 c$ & $54 \pm 3$ & $11 \pm 4$ & $34 \pm 2$ & $7.3 \pm 0.2$ \\
\hline & Potassium sorbate (E202) & $66 \pm 6$ & $13 \pm 4$ & $50 \pm 4 a$ & $50 \pm 5$ & $18 \pm 3$ & $38 \pm 4$ & $7.5 \pm 0.2$ \\
\hline & ANOVA $p$-value $(\mathrm{n}=27)^{2}$ & $<.001$ & $<.001$ & $<.001$ & $<.001$ & $<.001$ & $<.001$ & $<.001$ \\
\hline \multirow[t]{4}{*}{ ST } & 0 days & $63 \pm 7$ & $9 \pm 4$ & $43 \pm 8$ & $53 \pm 5$ & $14 \pm 5$ & $36 \pm 3$ & $7.3 \pm 0.4$ \\
\hline & 3 days & $60 \pm 6$ & $12 \pm 6$ & $42 \pm 8$ & $53 \pm 3$ & $15 \pm 5$ & $36 \pm 3$ & $7.3 \pm 0.2$ \\
\hline & 5 days & $63 \pm 6$ & $11 \pm 4$ & $44 \pm 7$ & $53 \pm 3$ & $15 \pm 3$ & $37 \pm 3$ & $7.3 \pm 0.2$ \\
\hline & ANOVA $p$-value $(\mathrm{n}=27)^{3}$ & .215 & .100 & .596 & .806 & .797 & .768 & .797 \\
\hline $\mathrm{CF} \times \mathrm{ST}$ & $p$-value $(\mathrm{n}=81)^{4}$ & .006 & .001 & .809 & $<.001$ & .001 & $<.001$ & $<.001$ \\
\hline
\end{tabular}

1 The results presented for each CF included the contribution of values measured in all ST; likewise, results for each ST were obtained considering the values measured for all CF.

${ }^{2}$ If $p<.050$, the corresponding parameter presented a significantly different value for at least one CF.

${ }^{3}$ If $p<.050$, the corresponding parameter presented a significantly different value for at least one ST.

${ }^{4} p<.050$ indicates a significant interaction among factors, thereby precluding performing multiple comparison tests. 
Table 4

Major (detected above 1\%) fatty acids (relative percentage) in cupcake formulations (CF) and storage time (ST). Results are presented as mean \pm standard deviation ${ }^{1}$.

\begin{tabular}{|c|c|c|c|c|c|c|c|c|c|c|c|c|}
\hline & & $\mathrm{C} 4: 0$ & C6:0 & C10:0 & $\mathrm{C} 12: 0$ & $\mathrm{C} 14: 0$ & $\mathrm{C} 16: 0$ & C18:0 & C18:1n9 & SFA & MUFA & PUFA \\
\hline \multirow[t]{4}{*}{ CF } & Control & $5 \pm 1$ & $3 \pm 1$ & $4.3 \pm 0.3$ & $4.5 \pm 0.4$ & $10.2 \pm 0.5$ & $32 \pm 1 \mathrm{ab}$ & $9.8 \pm 0.5$ & $23 \pm 1$ & $74 \pm 2$ & $25 \pm 1$ & $0.7 \pm 0.2$ \\
\hline & $\begin{array}{l}\text { Lemon balm extract rich in } \\
\text { rosmarinic acid (ERA) }\end{array}$ & $4 \pm 1$ & $3 \pm 1$ & $3.1 \pm 0.4$ & $3.5 \pm 0.3$ & $10.1 \pm 0.4$ & $33 \pm 1 \mathrm{a}$ & $9.8 \pm 0.3$ & $27 \pm 3$ & $70 \pm 3$ & $29 \pm 3$ & $0.6 \pm 0.2$ \\
\hline & Potassium sorbate (E202) & $5 \pm 1$ & $3 \pm 1$ & $3.3 \pm 0.5$ & $3.6 \pm 0.4$ & $10.2 \pm 0.4$ & $32 \pm 1 b$ & $9.8 \pm 0.4$ & $26 \pm 2$ & $71 \pm 2$ & $28 \pm 2$ & $0.6 \pm 0.2$ \\
\hline & ANOVA $p$-value $(\mathrm{n}=27)^{2}$ & $<.001$ & .235 & $<.001$ & $<.001$ & .560 & .001 & .846 & $<.001$ & $<.001$ & $<.001$ & .210 \\
\hline \multirow[t]{4}{*}{ ST } & 0 days & $4 \pm 1$ & $2.3 \pm 0.4$ & $3.2 \pm 0.5$ & $3.7 \pm 0.5$ & $10.0 \pm 0.4$ & $33 \pm 1 \mathrm{a}$ & $9.9 \pm 0.5$ & $28 \pm 3$ & $69 \pm 3$ & $30 \pm 3$ & $0.5 \pm 0.2$ \\
\hline & 3 days & $5 \pm 1$ & $3.2 \pm 0.5$ & $3.7 \pm 0.5$ & $4.0 \pm 0.5$ & $10.3 \pm 0.4$ & $32 \pm 1 \mathrm{ab}$ & $9.9 \pm 0.4$ & $24 \pm 1$ & $73 \pm 1$ & $27 \pm 1$ & $0.8 \pm 0.1$ \\
\hline & 5 days & $6 \pm 1$ & $4 \pm 1$ & $3.9 \pm 0.5$ & $3.8 \pm 0.4$ & $10.2 \pm 0.5$ & $32 \pm 1 b$ & $9.5 \pm 0.4$ & $23 \pm 2$ & $74 \pm 2$ & $25 \pm 2$ & $0.7 \pm 0.1$ \\
\hline & ANOVA $p$-value $(n=27)^{3}$ & $<.001$ & $<.001$ & .001 & .160 & .054 & .037 & .002 & $<.001$ & $<.001$ & $<.001$ & $<.001$ \\
\hline $\mathrm{CF} \times \mathrm{ST}$ & $p$-value $(\mathrm{n}=81)^{4}$ & $<.001$ & $<.001$ & .003 & .010 & .228 & .103 & $<.001$ & $<.001$ & $<.001$ & $<.001$ & $<.001$ \\
\hline
\end{tabular}

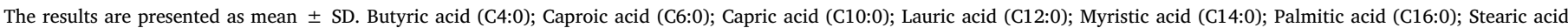
(C18:0); Oleic acid (C18:1n9); SFA-Saturated fatty acids; MUFA-Monounsaturated fatty acids; PUFA-Polyunsaturated fatty acids.

${ }^{1}$ The results presented for each CF included the contribution of values measured in all ST; likewise, results for each ST were obtained considering the values measured for all CF.

${ }^{2}$ If $p<.050$, the corresponding parameter presented a significantly different value for at least one CF.

${ }^{3}$ If $p<.050$, the corresponding parameter presented a significantly different value for at least one ST.

${ }^{4} p<.050$ indicates a significant interaction among factors, thereby precluding performing multiple comparison tests.

selected according to the stepwise method of LDA, considering the Wilks' $\lambda$ test. Only variables with a statistically significant classification performance $(p<.050)$ were selected in the obtained statistical models.

Regarding ST effect, the two defined discriminant functions included $100.0 \%$ (first function: $85.8 \%$; second function: $14.2 \%$ ) of the observed variance (Fig. 2A). From the initial 28 variables, only 10

(A)

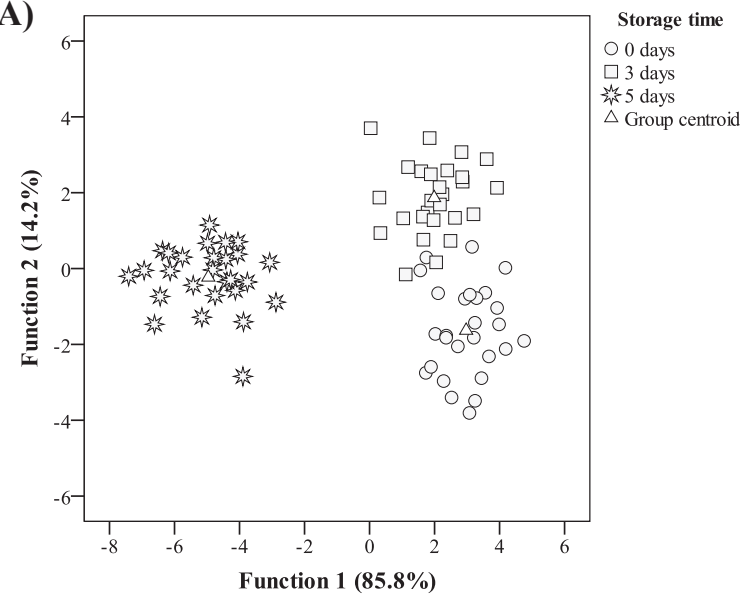

(B)

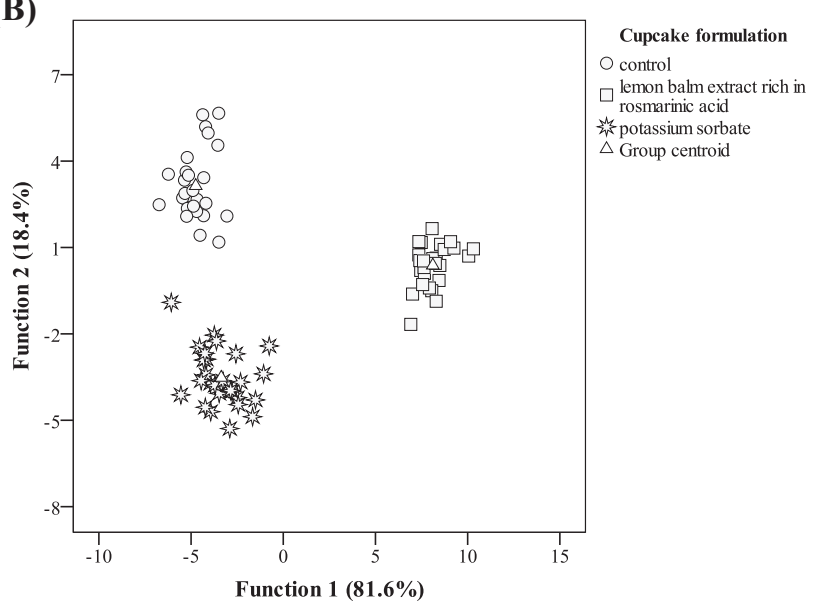

Fig. 2. Canonical discriminant functions coefficients defined from the evaluated parameters. A: Storage time effect. B: Cupcake formulation effect. (carbohydrates, fat, ash, glucose, sucrose, energy, $b^{*}$ (bottom), PUFA, DPPH scavenging activity and reducing power) were selected as having discriminant ability to separate samples corresponding to each ST. The first function was highly correlated to carbohydrates, energy and glucose, and its main contribution was the separation of markers corresponding to samples stored for 5 days, which might be characterized as having particularly high energy and carbohydrate levels in one side, and the lowest glucose contents, on the other. Function 2, in contrast, allowed separating samples corresponding to non-stored samples from those stored for 3 days, mainly due to the differences in sucrose and PUFA (both lower in non-stored samples) and DPPH scavenging activity (higher in non-stored samples). These are the variables with highest correlation with function 2. Overall, non-stored cupcakes showed higher similarity with those stored for 3 days, as also indicated by the classification performance of the discriminant model: $96.3 \%$ for the original grouped cases ( 3 of the 27 non-stored cupcakes were classified as having been stored for 3 days) and $93.8 \%$ (3 of the 27 non-stored cupcakes were classified as having been stored for 3 days; 2 of the 27 cupcakes stored for 3 days were classified as not having been stored; all cupcakes stored during 5 days were correctly classified) for the cross validated ones.

In what concerns $\mathrm{CF}$ effect, the two defined discriminant functions included $100.0 \%$ (first function: $81.6 \%$; second function: $18.4 \%$ ) of the observed variance (Fig. 2B). The model selected 12 variables ( $L^{*}$ (top), $a^{*}$ (top and bottom), $b^{*}$ (top and bottom), pH, C6:0, C10:0, SFA, MUFA, DPPH scavenging activity and reducing power) as having significant capacity to discriminate samples corresponding to each CF. As observable in Fig. 2B, function 1 separated cupcakes functionalized with ERA from the remaining samples, mostly due to the values of $L^{*}, a^{*}$ and $b^{*}$ (all with lower values in cupcakes prepared with ERA) at the top part of cupcakes. The three variables with highest correlation with function 2 were reducing power and DPPH scavenging activity (higher $\mathrm{EC}_{50}$ values in control cupcakes) C10:0 and 12:0 (higher in control cupcakes) and $\mathrm{pH}$ (lower in control cupcakes), thereby being effective in separating control samples from those with added potassium sorbate. In this case, the classification performance was $100 \%$ accurate for originally grouped cases and $98.8 \%$ for cross-validated ones.

\section{Conclusions}

Overall, cupcake formulation exerted more pronounced effects than storage time over the parameters evaluated in these cupcakes. Energy level, carbohydrates, sucrose, glucose and PUFA were the variables with highest differences among different ST, while $L^{*}$ (top), $a^{*}$ (top), $b^{*}$ (top), reducing power, DPPH scavenging activity, C10:0, 12:0 and $\mathrm{pH}$ 
presented the most significant changes according to CF effect. In general, and in view of the strong bioactivity (antioxidant, antibacterial and antifungal activities) exhibited by ERA, the obtained results reinforce its suitability to be used as natural additive to provide advantageous properties to bakery products, potentially benefiting consumers' health.

\section{Acknowledgements}

The authors are grateful to the Foundation for Science and Technology (FCT, Portugal) and FEDER under Programme PT2020 for financial support to CIMO (UID/AGR/00690/2013), REQUIMTE (UID/ QUI/50006/2013 - POCI/01/0145/FERDER/007265), Associate Laboratory LSRE-LCM (Project POCI-01-0145-FEDER-006984), C. Caleja (SFRH/BD/93007/2013) grant and L. Barros contract. This work was also funded by the European Structural and Investment Funds (FEEI) through the Regional Operational Program North 2020, within the scope of Project NORTE-01-0145-FEDER-023289: DeCodE. The authors also thank to company Mais Ervas, Lda (Alfandega da Fé, Portugal), for providing the $M$. officinalis samples.

\section{References}

Abdel-Moemin, A. R. (2016). Effect of Roselle calyces extract on the chemical and sensory properties of functional cupcakes. Food Science and Human Wellness, 5, 230-237.

AOAC (2016). (20). AOAC official methods of analysisAOAC International.

Barros, L., Dueñas, M., Dias, M. I., Sousa, M. J., Santos-Buelga, C., \& Ferreira, I. C. F. R. (2013). Phenolic profiles of cultivated, in vitro cultured and commercial samples of Melissa officinalis L. infusions. Food Chemistry, 136, 1-8.

Barros, L., Pereira, E., Calhelha, R. C., Dueñas, M., Carvalho, A. M., Santos-Buelga, C., \& Ferreira, I. C. F. R. (2013). Bioactivity and chemical characterization in hydrophilic and lipophilic compounds of Chenopodium ambrosioides L. Journal of Functional Foods, 5, 1732-1740.

Bera, D., Lahiri, D., \& Nag, A. (2006). Studies on a natural antioxidant for stabilization of edible oil and comparison with synthetic antioxidants. Journal of Food Engineering, 74, 542-545.

Bessada, S. M., Barreira, J. C. M., Barros, L., Ferreira, I. C. F. R., \& Oliveira, M. B. P. P. (2016). Phenolic profile and antioxidant activity of Coleostephus myconis (L.) Rchb. f.: An underexploited and highly disseminated species. Industrial Crops and Products, 89, $45-51$.

Caleja, C., Barros, L., Antonio, A. L., Carocho, M., Oliveira, M. B. P. P., \& Ferreira, I. C. F. R. (2016). Fortification of yogurts with different antioxidant preservatives: A comparative study between natural and synthetic additives. Food Chemistry, 210, $262-268$.

Caleja, C., Barros, L., Antonio, A. L., Ciric, A., Barreira, J. C. M., Soković, M., ... Ferreira, I. C. F. R. (2015). Development of a functional dairy food: Exploring bioactive and preservation effects of chamomile (Matricaria recutita L.). Journal of Functional Foods, $16,114-124$.

Caleja, C., Barros, L., Antonio, A. L., Ciric, A., Soković, M., Oliveira, M. B. P. P., Ferreira, I. C. F. R. (2015). Foeniculum vulgare Mill. as natural conservation enhancer and health promoter by incorporation in cottage cheese. Journal of Functional Foods, $12,428-438$.

Caleja, C., Barros, L., Antonio, A. L., Oliveira, M. B. P. P., \& Ferreira, I. C. F. R. (2017). A comparative study between natural and synthetic antioxidants: Evaluation of their performance after incorporation into biscuits. Food Chemistry, 216, 342-346.

Caleja, C., Barros, L., Prieto, M. A., Barreiro, M. F., Oliveira, M. B. P. P., \& Ferreira, I. C. F. R. (2017). Extraction of rosmarinic acid from Melissa officinalis L. by heat-, microwave- and ultrasound-assisted extraction techniques: A comparative study through response surface analysis. Separation and Purification Technology, 186, 297-308.

Carocho, M., Barreira, João C. M., Barros, L., Bento, Albino., Cámara, M., Morales, P., \& Ferreira, Isabel C. F. R. (2015). Traditional pastry with chestnut flowers as natural ingredients: an approach of the effects on nutritional value and chemical composition. Journal of Food Composition and Analysis, 44, 93-101.

Carocho, M., Barreira, J. C. M., Bento, A., Fernández-Ruiz, V., Morales, P., \& Ferreira, I. C. F. R. (2016). Chestnut and lemon balm based ingredients as natural preserving agents of the nutritional profile in matured "Serra da Estrela" cheese. Food Chemistry, 204, 185-194.

Carocho, M., Barreira, João C. M., Bento, Albino, Morales, P., \& Ferreira, Isabel C. F. R. (2014). Chestnut flowers as functionalizing agents to enhance the antioxidant properties of highly appreciated traditional pastry. Food and Function, 5, 2989-2995.
Carocho, M., Barros, L., Barreira, J. C. M., Calhelha, R. C., Soković, M., Fernández-Ruiz, V., ... Ferreira, I. C. F. R. (2016). Basil as functional and preserving ingredient in "Serra da Estrela" cheese. Food Chemistry, 207, 51-59.

Carocho, M., Barros, L., Calhelha, R. C., Ćirić, A., Soković, M., Santos-Buelga, C., Ferreira, I. C. F. R. (2015). Melissa officinalis L. decoctions as functional beverages: a bioactive approach and chemical characterization. Food and Function, 6, 2240-2248.

Carocho, M., Morales, P., \& Ferreira, I. C. F. R. (2015). Natural food additives: Quo vadis? Trends Food Science and Technology, 45, 284-295.

Dias, M. I., Barros, L., Sousa, M. J., \& Ferreira, I. C. F. R. (2012). Systematic comparison of nutraceuticals and antioxidant potential of cultivated, in vitro cultured and commercial Melissa officinalis samples. Food and Chemical Toxicology, 50, 1866-1873.

Döring, A. S., Pellegrini, E., Batola, M. D., Nali, C., Lorenzini, G., \& Petersen, M. (2014). How do background ozone concentrations affect the biosynthesis of rosmarinic acid in Melissa officinalis? Journal of Plant Physiology, 171, 35-41.

El Ouadi, Y., Manssouri, M., Bouyanzer, A., Majidi, L., Bendaif, H., Elmsellem, H., .. Hammouti, B. (2017). Essential oil composition and antifungal activity of Melissa officinalis originating from north-Est Morocco, against postharvest phytopathogenic fungi in apples. Microbial Pathogenesis, 107, 321-326.

Fernandes, Â., Antonio, A. L., Barreira, J. C. M., Oliveira, M. B. P. P., Martins, A., \& Ferreira, I. C. F. R. (2012). Effects of gamma irradiation on physical parameters of Lactarius deliciosus wild edible mushrooms. Postharvest Biology and Technology, 74, 79-84.

Gandhi, A. P., Kotawaliwale, N., Kawalkar, J., Srivastava, D. C., Parihar, V. S., \& Raghu Nadh, P. (2001). Effect of incorporation of defatted soy flour on the quality of sweet biscuits. Journal of Food Science and Technology, 38(502-503), 7.

Guimarães, R., Barros, L., Dueñas, M., Carvalho, A. M., Queiroz, M. J. R. P., SantosBuelga, C., \& Ferreira, I. C. F. R. (2013). Characterisation of phenolic compounds in wild fruits from Northeastern Portugal. Food Chemistry, 141, 3721-3730.

Jeddou, K. B., Bouaziz, F., Zouari-Ellouzi, S., Chaari, F., Ellouz-Chaabouni, S., EllouzGhorbel, R., \& Nouri-Ellouz, O. (2017). Improvement of texture and sensory properties of cakes by addition of potato peel powder with high level of dietary fiber and protein. Food Chemistry, 217, 668-677.

Kamdem, J. P., Adeniran, A., Boligon, A. A., Klimaczewski, C. V., Elekofehinti, O. O., Hassan, W., ... Athayde, M. L. (2013). Antioxidant activity, genotoxicity and cytotoxicity evaluation of lemon balm (Melissa officinalis L.) ethanolic extract: Its potential role in neuroprotection. Industrial Crops and Products, 51, 26-34.

Kim, J.-M., \& Shin, M. (2014). Effects of particle size distributions of rice flour on the quality of gluten-free rice cupcakes. LWT - Food Science and Technology, 59, 526-532.

Lennerz, B. S., Vafai, S. B., Delaney, N. F., Clish, C. B., Deik, A. A., Pierce, K. A., et al (2015). Effects of sodium benzoate, a widely used food preservative, on glucose homeostasis and metabolic profiles in humans. Molecular Genetics and Metabolism, 114, 73-79.

Maqsood, S., Benjakul, S., \& Shahidi, F. (2013). Emerging role of phenolic compounds as natural additives in fish and fish products. Critical Reviews in Food Science and Nutrition, 53, 162-179.

Pereira, E., António, A. L., Barreira, J. C. M., Barros, L., Bento, Albino, \& Ferreira, I. C. F. R. (2015). Gamma irradiation as a practical alternative to preserve the chemical and bioactive wholesomeness of widely used aromatic plants. Food Research International, 67, 338-348.

Pereira, E., Antonio, A. L., Rafalski, A., Barreira, J. C. M., Barros, L., Oliveira, M. B. P. P. \& Ferreira, I. C. F. R. (2017). Electron-beam irradiation as an alternative to preserve nutritional, chemical and antioxidant properties of dried plants during extended storage periods. LWT - Food Science and Technology, 82, 386-395.

Roby, M., Sarhan, M., Selim, K., \& Khalel, K. (2013). Antioxidant and antimicrobial activities of essential oil and extracts of fennel (Foeniculum vulgare L.) and chamomile (Matricaria chamomilla L.). Industrial Crops and Products, 44, 437-445.

Sciarini, L. S., Ribotta, P. D., León, A. E., \& Pérez, G. T. (2012). Incorporation of several additives into gluten free breads: Effect on dough properties and bread quality. Journal of Food Engineering, 111, 590-597.

Shakeri, A., Sahebkar, A., \& Javadid, B. (2016). Melissa officinalis L. - A review of its traditional uses, phytochemistry and pharmacology. Journal of Ethnopharmacology, 188, 204-228.

Shim, S.-M., Seo, S. H., Lee, Y., Moon, G.-I., Kim, M.-S., \& Park, J.-H. (2011). Consumers' knowledge and safety perceptions of food additives: Evaluation on the effectiveness of transmitting information on preservatives. Food Control, 22, 1054-1060.

Singh, N., Jha, A., Chaudhary, A., \& Upadhyay, A. (2012). Enhancement of the functionality of bread by incorporation of Shatavari (Asparagus racemosus). Journal of Food Science and Technology, 51, 2038-2045.

Soković, M., Glamoćlija, J., Marin, M. D., Brkić, D., \& van Griensven, L. J. L. D. (2010). Antibacterial effects of the essential oils of commonly consumed medicinal herbs using an in vitro model. Molecules, 15, 7532-7546.

Soković, M., \& van Griensven, L. J. L. D. (2006). Antimicrobial activity of essential oils and their components against the three major pathogens of the cultivated button mushroom, Agaricus bisporus. European Journal of Plant Pathology, 116, 211-224.

Xavier, A. A. O., Carvajal-Lérida, I., Garrido-Fernández, J., \& Pérez-Gálvez, A. (2017). In vitro bioaccessibility of lutein from cupcakes fortified with a water-soluble lutein esters formulation. Journal of Food Composition and Analysis in press. 